\title{
Effect of Heavy Metals Stress on Polyphenolic Compounds in Hydroalcoholic Extract of Basil (Ocimum basilicum L.)
}

\author{
Amir Rahimi (Corresponding author's) \\ Urmia University, Faculty of Agriculture, Department of Agronomy, Urmia/Iran \\ E-mail: e.rahimi@urmia.ac.ir; emir10357@gmail.com \\ Fatemeh Ahmadi \\ Urmia University, Faculty of Agriculture, Department of Soil Science, Urmia/Iran \\ E-mail: fa.ahmadi@urmia.ac.ir \\ Gulen Ozyazici \\ Siirt University, Faculty of Agriculture, Department of Field Crops, Siirt/Turkey \\ E-mail:gulenozyazici@siirt.edu.tr
}

\begin{abstract}
Heavy metals are important environmental pollutants and can affect the lives of plants and subsequently the lives of humans and other organisms. On the other hand, medicinal plants and their polyphenolic constituents have received much attention due to their confirmed positive effects on human health. Therefore, in this study, the effect of heavy metal lead, one of the most important toxic metals in the environment, on the polyphenolic compounds of the basil medicinal plant (Ocimum basilicum L.) was investigated. The purpose of this study was to evaluate the resistance of this medicinal plant to stress induced by lead toxic metal and also the content of polyphenolic compounds. The method was planted in basil greenhouse and factorial experiment in a completely randomized design with three replications. Lead metal treatment with 0, 25, 50 and 75 ppm levels, EDTA treatment with 0 and $1 \mathrm{mmol} \mathrm{L}^{-1}$ and humic acid treatment with 0 and $2 \mathrm{~kg} \mathrm{ha}^{-1}$ were applied. After harvesting at flowering stage, the hydroalcoholic extract of dry shoots was prepared and the amount of polyphenolic compounds in the extracts was measured. The results showed that lead in soil significantly changed the content of polyphenolic compounds of basil. Increasing the amount of lead metal generally decreased the polyphenolic compounds of the plant. The presence of EDTA also increased polyphenolic compounds and reduced the content of polyphenolic compounds using humic acid.
\end{abstract}

Keywords: Antioxidant, EDTA, Humic acid, Lead

DOI: $10.7176 / \mathrm{JSTR} / 5-12-06$

\section{Introduction}

Herbs have been used for a large range of purposes including medicine, nutrition, flavorings, beverages, dyeing, repellents, fragrances, cosmetics, charms, smoking, and industrial uses. Since prehistoric times, herbs were the basis for nearly all medicinal therapy until synthetic drugs were developed in the nineteenth century (Rojas, et al., 2016). Today's advanced life, along with the comfort and prosperity it brings to man, has created new problems for the environment. These problems include increased environmental pollution such as chemical pollutants. Today, environmental pollution is one of the major problems that human societies face. Population growth, urban development, agricultural and industrial development and their inadequate management and human interference with nature have increased environmental pollution (Di Lorenzo et al., 2015). Heavy metals are pollutants that affect the lives of plants and subsequently the lives of humans and other organisms. Heavy metals such as lead and cadmium are of particular importance due to their dire consequences on environmental pollution (Baseer, and Jain, 2016). In addition, these pollutants enter water, soil and plants from various sources and uses and ultimately into the human and animal food chain and leave their detrimental effect (Pulford and 
Watson, 2003; Nguyen et al., 2010). Plants react in two ways in the environments with high concentrations of heavy metals: The first mechanism is avoidance mechanism through which the plants prevent from absorption and transport of metals into their organs. These plants are called nonaccumulator. The second mechanism is metals accumulation mechanism through which the plants can have a huge potential for absorption of metals by the roots and transport and store them in the stems. These plants are called hyper accumulator (Panita, 2015).

There is growing recognition that many phenolic secondary metabolites present in foodstuffs may possibly exert beneficial effects on human health (Joshi, 2017). This may to some degree be mediated via antioxidant actions, but a range of more specific pharmacological effects have also been proposed (Baker et al., 2000). Given this background, there may be favorable consequences for the general health of Western populations as a result of optimizing the phenolic content of the diet (Kostik and Bauer, 2015). These plants can be used to remove and cleanup the soils contaminated by heavy metals through phytoremediation process (Lazarević and Carović-Stanko, 2018).

Secondary metabolites are chemicals unique to plants and have specific physiological roles in plants (Heldt, 2005). The presence of secondary metabolites in plants, sometimes known as phytochemicals, brings with them properties that are the source and reason for their use in traditional medicine and herbal remedies (Saroya, 2011). Today, herbal medicines are widely used and used not only by the general public but also by scientists and pharmacists. Phenols and flavonoids are substances that have received much attention due to their antioxidant properties (Manach, et al., 2004). The presence of these substances for the plant has beneficial physiological effects. On the other hand, consumption of these substances, or polyphenolic compounds in general, protects the human body against the damage caused by free radicals, which can lead to many diseases (Harisaranraj, et al. ., 2008).

Basil with the scientific name Ocimum basilicum L. is one of the most important plants of the Lamiaceae (Makari and Kintzios, 2008). Different species of basil have been used for medicinal, spice, and vegetable purposes for many years (Kruger, et al., 2002; Koca and Karaman, 2015). The benefits of this plant such as blood sugar lowering, antispasmodic, analgesic, blood pressure lowering, fever reducing, body adaptation to stressors, enhance the body's natural activity and its antioxidant and anti-inflammatory properties ( Hope Beygi, 2000; Juliani and Simon, 2002). Medicinal properties and the presence of aromatic compounds make basil one of the most famous herbs in the world. Basil essential oil and its extracts are widely used in food and perfume industries (Simon, 1992; Jayasinghe et al., 2003).

Due to the importance of heavy metal stress on plant life and the role of polyphenolic materials in medicinal plants, the effect of lead toxic metal on the content of polyphenolic compounds of basil was investigated. Humic acid and EDTA were also used to control stress induced by lead metal.

\section{Materials and Methods}

The trial was done at the experimental fields of Urmia University, Iran during 2017-2018. The experimental land was plowed at the optimum moisture level (field capacity) and leveled. Sowing were done in an open field at the Department of Agronomy, Faculty of Agriculture, Urmia University. The seeds were sowed in plastic pots filled with soil, sand, and peat moss substrate as a material to germination. After sowing was irrigated regularly depending on field conditions and development stage of plants. Seedlings were harvested and planted in the experimental field. Five soil samples were collected randomly from various sites. Sampling in each site was done in 0-30 cm depth in autumn before application of fertilizers, using stainless-steel auger. soil samples were mixed together to form a combined sample, and collected using polyethylene bags and pre-treatment by being air-dried at room temperature $\left(25 \pm 1^{\circ} \mathrm{C}\right)$, ground and sieved through 2 - $\mathrm{mm}$ for physiochemical analysis.

Soil analysis was performed based on standard methods (Rowell, 2014). Soil pH was measured using 1:5 soil to water ratio suspension with a glass electrode $\mathrm{pH}$ meter (model inolab $\mathrm{pH} 7110$ ). Soil electrical conductivity (EC) was measured using a glass electrode (model 712 conductometer) after mixing the soil with water $(1: 5 \mathrm{w} / \mathrm{v})$. Organic matter was determined according to the walky-black method, which is based on the oxidation of organic matter with $\mathrm{K}_{2} \mathrm{Cr}_{2} \mathrm{O}_{7}$ and $\mathrm{H}_{2} \mathrm{SO}_{4}$ and titration with $\mathrm{FeSO}_{4}$. Soil available $\mathrm{P}($ Olsen-P) is the official factor for assessing soil plant available (Lu, 1999). Briefly, $1 \mathrm{~g}$ of aired-dried soil sample and $20 \mathrm{ml}$ of $\mathrm{NaHCO}_{3}\left(0.5 \mathrm{~mol} \mathrm{~L}^{-1}, \mathrm{pH} 8.5\right)$ were placed into a $50 \mathrm{ml}$ extraction bottle; and the bottles were shaken mechanically for $30 \mathrm{~min}$ at room temperature. The suspension was filtered through a Whatman No. 42 free filter paper. The P concentrations in the filtrates were measured by the colorimetric method using ascorbic acid at $820 \mathrm{~nm}$ by spectrophotometer (model Varian Cary 100). Available potassium (K) concentration was determined using $1 \mathrm{M}$ Ammonium Acetate. Particle-size distribution was determined by the hydrometer method (Kruma et al., 2008; Suanarunsawat et al., 2014). The experiment was conducted in a factorial randomized complete design with three replications. Different factors including lead treatment at four levels $(0,25,50$ and $75 \mathrm{ppm})$, humic acid at two levels

58 | $P$ a g e 
( 1 and $\left.2 \mathrm{~kg} \mathrm{ha}^{-1}\right)$ and EDTA treatment $\left(1\right.$ and $\left.2 \mathrm{mmol} \mathrm{L}^{-1}\right)$. The pots were given a week after the treatments and then 15 basil seeds were planted in each pot. The plants were harvested at the flowering stage and the hydroalcoholic extract of the shoots was prepared by water-ethanol solvent (25:75) and the total content of their polyphenolic compounds was measured. The amount of total phenolics in the herb extracts was determined with the Folin-Ciocalteu reagent according to the method of Slinkard and Singleton (10) using gallic acid as a standard. Samples $(200 \mu \mathrm{L}$, two replicates) were introduced into test cuvettes, and then $1.0 \mathrm{~mL}$ of Folin-Ciocalteu's reagent and $0.8 \mathrm{~mL}$ of $\mathrm{Na}_{2} \mathrm{CO}_{3}(7.5 \%)$ were added. The absorbance of all samples was measured at $765 \mathrm{~nm}$ using the Shimadzu UV-Vis spectrophotometer after incubating at $30^{\circ} \mathrm{C}$ for $1.5 \mathrm{~h}$. Results were expressed as milligrams of gallic acid equivalent (GAE) per gram of fresh weight. Correlation and regression analyses of total phenolic content were carried out using the statistical program in Microcal Origin (Microcal Software Inc., Northampton, MA). Data were subjected to analysis of variance, and means were compared by least significant difference (LSD) used in NCSS (11). Differences at $\mathrm{p}<0.05$ were considered to be significant.

\section{Results and discussion}

Selected chemical and physical properties of the five studied soils are shown in Table 1. According to the obtained $\mathrm{pH}$, soil classified as neutral (ranging from 6.5 to 7.5 ) but it is not alkaline soil due to the low EC (less than $2 \mathrm{dS} \mathrm{m}^{-1}$ ). As well as, relatively high organic carbon (1.14\%) and loamy texture of studies soil samples relevant the appropriate conditions was performed for growing of Basil (Ocimum basilicum $\mathrm{L}$.) . Based on soil nutrients analysis, no fertilization was necessary in studied soils ( $\mathrm{P}$ and $\mathrm{K}$ concentrations more than $15 \mathrm{mg} \mathrm{kg}^{-1}$ and $60 \mathrm{mg} \mathrm{kg}^{-1}$ respectively). The use of organic manures and chemical fertilizers in Iranian agricultural farms is more than the needs of plants and soil and water research institute recommendations, which leads to the accumulation of organic and inorganic compounds in soil and their decomposition over time (Pingale et al., 2012).

Table 1. Mean physiochemical characteristics of studied combined soil sample

\begin{tabular}{ccccccccc}
\hline $\mathrm{pH}$ & $\begin{array}{c}\mathrm{EC} \\
\left(\mathrm{dS} \mathrm{m}^{-1}\right)\end{array}$ & $\begin{array}{c}\mathrm{OC} \\
(\%)\end{array}$ & $\begin{array}{c}\text { Olsen-P } \\
\left(\mathrm{mg} \mathrm{kg}^{-1}\right)\end{array}$ & $\begin{array}{c}\text { Available }-\mathrm{K} \\
\left(\mathrm{mg} \mathrm{kg}^{-1}\right)\end{array}$ & $\begin{array}{c}\mathrm{CaCO}_{3} \\
(\%)\end{array}$ & $\begin{array}{c}\text { Sand } \\
(\%)\end{array}$ & $\begin{array}{c}\text { Silt } \\
(\%)\end{array}$ & $\begin{array}{c}\text { Clay } \\
(\%)\end{array}$ \\
\hline 7.33 & 0.06 & 1.14 & 37.60 & 166 & 9.0 & 44 & 32 & 24 \\
\hline
\end{tabular}

The content of polyphenolic compounds of basil medicinal plant in the presence of different amounts of lead metal as well as the use and non-use of EDTA and humic acid were measured as factorial. The results of the analysis of variance for this study are shown in Table 2. As can be seen, all three treatments of $\mathrm{Pb}, \mathrm{EDTA}$ and humic acid had a significant effect on the content of polyphenolic compounds of basil plant at $1 \%$ probability level. Figure 1 shows the average amount of polyphenolic compounds in the basil extract at different levels of lead. This graph shows that the amount of polyphenolic compounds decreases with increasing $\mathrm{Pb}$ content from $0 \mathrm{ppm}$ to $50 \mathrm{ppm}$. This is due to the toxicity of lead heavy metal that its presence is affected by its increased oxidative stress in the basil plant, its chemical constituents (Michalak, 2006).

Table 2. Analysis of variance for the amount of polyphenolic compounds in basil

\begin{tabular}{|c|c|c|}
\hline Variation & Degree of freedom & average of squares \\
\hline $\mathrm{Pb}$ & 3 & $0.0277^{* *}$ \\
\hline EDTA & 1 & $0.0122^{* *}$ \\
\hline Humic acid & 1 & $0.0009^{* *}$ \\
\hline Error & 32 & 0.0001 \\
\hline
\end{tabular}

${ }^{* *}$ Significance at $1 \%$ probability level

Figure 2 also shows that the content of polyphenolic compounds increases again at $75 \mathrm{ppm}$. Possibly due to the high toxicity of lead metal, the amount of polyphenolic compounds present in the basil plant has increased to counteract the stress resulting from free radicals produced by lead metal. Because polyphenolic compounds have antioxidant properties and can be effective in neutralizing free radicals 
(Bashmakov et al., 2005; Maleki, et al., 2017). It is therefore observed that different levels of lead metal can have different effects on polyphenolic compounds.

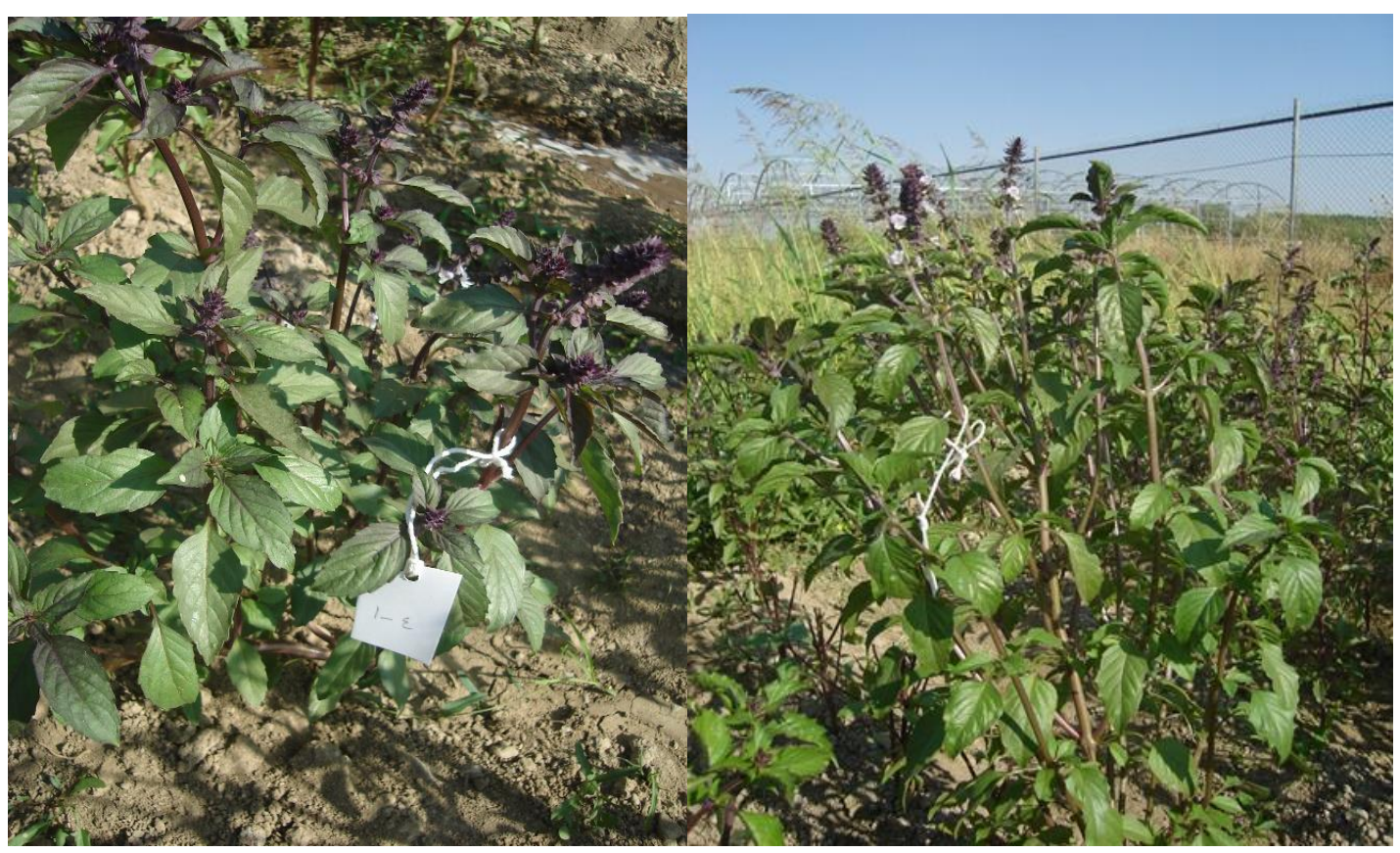

Figure 1. The Ocimum basilicum L. grown in open field condition

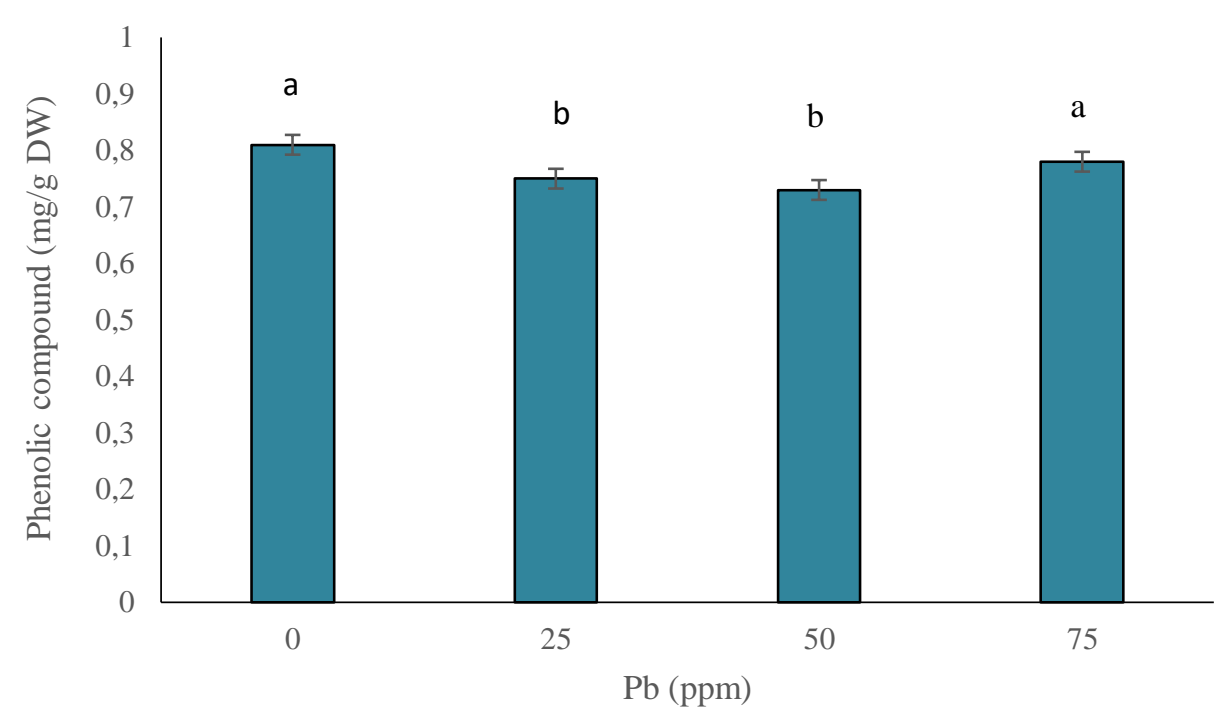

Figure 2. The effect of different levels of lead on the mean amount of polyphenolic compounds of basil 

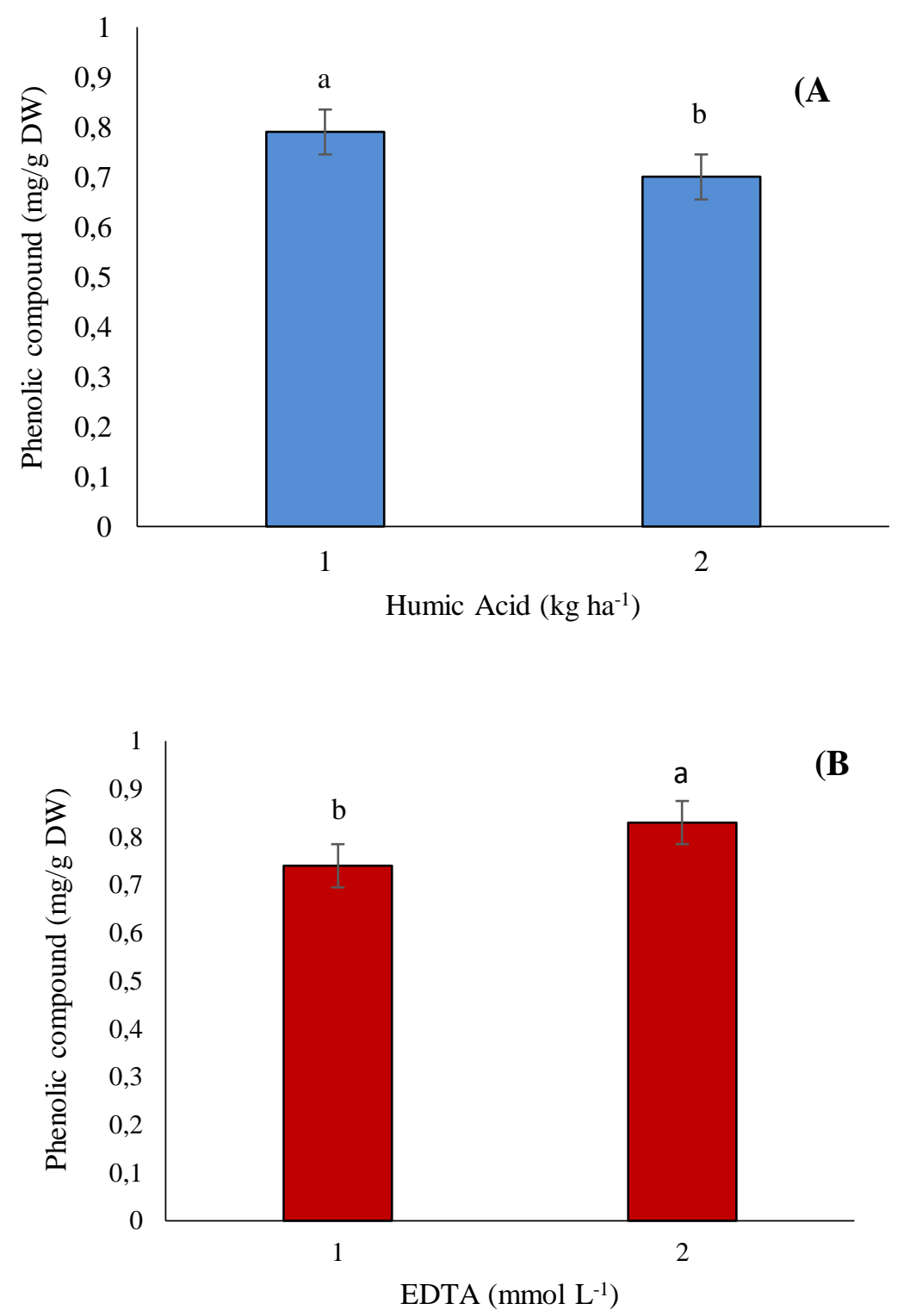

Figure 3. The effect of different levels of humic acid (A) and EDTA (B) on phenolic compounds of basil

Figure 3 shows the amount of polyphenolic compounds of basil in the presence and absence of humic acid (Part A) and in the presence and absence of EDTA (Part B). The results show that using humic acid the amount of basil polyphenolic compounds is reduced to a small amount. Humic substances have chelating compounds that can interact with metallic elements and thereby affect their effects. They, on the other hand, provide the plant with the necessary nutrients and affect their life and physiological properties.

Part B of Figure 3 shows that the use of $2 \mathrm{mmol} \mathrm{L}^{-1}$ of EDTA can increase the amount of polyphenolic compounds of basil in comparison to the non-use of EDTA. EDTA, with its chelating properties, improves the biological availability of essential metals for the plant and, on the other hand, controls the toxicity of lead-heavy metals (Miladinova-Georgieva, et al., 2018). The dual effect that heavy metal has on the content of polyphenolic compounds of basil, as explained in Figure 1, justifies the different effect of humic acid and EDTA on polyphenolic compounds of basil. Same results were found by Harisaranraj 
et al (2008). They reported that the phenolic content and composition of the plant depend on genetic and plant factors and that many factors such as climate, soil, height, species, and extraction methods effect the secondary plant metabolites, including phenolic compounds and effective antioxidant properties. Following the study, it was found that the content of phenolic compounds was higher in areas with higher light intake than in other areas. It has been suggested that the activity of the enzymes involved in the production of phenolic compounds changes under different climatic conditions (Maleki et al., 2017).

\section{Conclusion}

In this study, the effect of heavy metal lead, one of the most important toxic metals in the environment, on the polyphenolic compounds of the basil medicinal plant (Ocimum basilicum L.) was investigated. The purpose of this study was to evaluate the resistance of this medicinal plant to stress induced by lead toxic metal and also the content of polyphenolic compounds. The method was planted in basil greenhouse and factorial experiment in a completely randomized design with three replications. Lead metal treatment with $0,25,50$ and $75 \mathrm{ppm}$ levels, EDTA treatment with 0 and $1 \mathrm{mmol} \mathrm{L}^{-1}$ and humic acid treatment with 0 and $2 \mathrm{~kg} \mathrm{ha}^{-1}$ were applied. After harvesting at flowering stage, the hydroalcoholic extract of dry shoots was prepared and the amount of polyphenolic compounds in the extracts was measured. The results showed that lead in soil significantly changed the content of polyphenolic compounds of basil. Increasing the amount of lead metal generally decreased the polyphenolic compounds of the plant. The presence of EDTA also increased polyphenolic compounds and reduced the content of polyphenolic compounds using humic acid.

Declarations of interest: The authors declare that they have no conflict of interest.

\section{References}

Baker, A.J.M., McGrath, S.P., Reeves, R.D., Smith, J.A.C. (2000). Metal hyperaccumulator plants: A review of the ecology and physiology of a biological resource for phytoremediation of metalpolluted soils. In: Phytoremediation of contaminated soil and water. (Eds.): N. Terry and G. Banuelos. USA 7 Lewis publishers, pp. 313-375.

Bashmakov, D.I., Lukatkin, A.S., Revin, V.V. (2005). Growth of maize seedlings affected by different concentration of heavy metals. Ekologija, 3: 22-27.

Baseer, M., Jain, K. (2016). Review of botany, phytochemistry, pharmacology, contemporary applications and toxicology of Ocimum sanctum. International Journal of Pharmacy and Life Sciences, 7(2): 4918-4929.

Di Lorenzo, C., Ceschi, A., Kupferschmidt, H., Lüde, S., De Souza Nascimento, E., Dos Santos, A., Finglas, P. (2015). Adverse effects of plant food supplements and botanical preparations: a systematic review with critical evaluation of causality. British Journal of Clinical Pharmacology, 79(4): 578-592.

Harisaranraj, R., Prasitha, R., Babu, S.S., Suresh, K. (2008). Analysis of nnter-species relationships of Ocimum species using RAPD Markers. Ethnobotanical Leaflets, 12: 609-613.

Heldt, H.W. \& Piechulla, B. (2005). Plant Biochemistry, Third edition, Elsevier, London.

Joshi, R. K. (2017). Phytoconstituents, traditional, medicinal and bioactive uses of Tulsi (Ocimum sanctum L.): a review. Journal of Pharmacognosy Phytochemistry, 6(2): 261-264.

Juliani, H. R.\& Simon, J. E. (2002). Antioxidant activity of basil. Trends in new crops and new uses. ASHS Press, Alexandria, VA, 575(9).

Jayasinghe, C., Gotoh, N., Aoki, T., Wada, S. (2003). Phenolics composition and antioxidant activity of sweet basil (Ocimum basilicum L.). Journal of Agricultural and Food Chemistry, 51(15): 44424449.

Koca, N. \& Karaman, Ş. (2015). The effects of plant growth regulators and L-phenylalanine on phenolic compounds of sweet basil. Food Chemistry, 166: 515-521. 
Kostik, V. \& Bauer, B. (2015). Bioactive compounds of Rosa canina L. biotypes from spontaneous flora of Republic of Macedonia. In: 2nd International Conference on Natural Products Utilization and safety, (14-17 October), Plovdiv, Bulgaria.

Kruger, H., Wetzel, S.B., Zeiger, B. (2002). The chemical variability of Ocimum Species, Journal of Herbs, Spices and Medicinal Plants. 9(4): 335-344.

Kruma, Z., Andjelkovic, M., Verhe, R., Kreicbergs, V., Karklina, D., Venskutonis, P. (2008). Phenolic compounds in basil, oregano and thyme. Foodbalt, 5(7): 99-103.

Lazarević, B. \& Carović-Stanko, K. (2018). Effect of arbuscular mycorrhizae on phosphorus deficit stress during early development stage of basil (Ocimum basilicum L.). In 10th Conference on Medicinal and Aromatic Plants of Southeast European Countries, p.59.

Makari, O. \& Kintzios, S. (2008). Ocimum sp. (basil): Botany, cultivation, pharmaceutical properties and biotechnology, Journal of Herbs, Spices and Medicinal Plants, 13: 123-150.

Maleki, M., Ghorbanpour, M., Kariman, K. (2017). Physiological and antioxidative responses of medicinal plants exposed to heavy metals stress. Plant Gene, 11: 247-254.

Manach, C., Scalbert, A., Morand, C., Remesy, C., Jimenez, L. (2004). Polyphenols food sources and bioavailability. The American Journal of Clinical Nutrition, 79(5): 727-747.

Michalak, A. (2006). Phenolic compounds and their antioxidant activity in plants growing under heavy metal stress. Polish Journal of Environmental Studies, 15(4):523-530.

Miladinova-Georgieva, K., Ivanova, K., Georgieva, T., Geneva, M., Petrov, P., Stancheva, I., Markovska, Y. (2018). EDTA and citrate impact on heavy metals phytoremediation using paulownia hybrids. International Journal of Environment and Pollution, 63(1-2):31-46.

Nguyen, P. M., Kwee, E. M., Niemeyer, E. D. (2010). Potassium rate alters the antioxidant capacity and phenolic concentration of basil (Ocimum basilicum L.) leaves. Food Chemistry, 123(4): $1235-1241$.

Pingale, S. S., Firke, N. P., Markandeya, A. G. (2012). Therapeutic activities of Ocimum tenuiflorum accounted in last decade: A review. Journal of Pharmacy Research, 5(4): 2215-2220.

Pulford, I. D., \& Watson, C. (2003). Phytoremediation of heavy metal-contaminated land by trees, a review. Environment International, 29(4): 529-540.

Prasongdee, P. (2015). Extraction and bioactivities of Thai basil (Ocimum basilicum L.). Master Thesis. Institute of Agricultural Technology. Suranaree University of Technology. 110 p.

Rowell, D. L. (2014). Soil science: Methods and applications. Routledge. 368 p.

Rojas, J., Londoño, C., Ciro, Y. (2016). The health benefits of natural skin UVA photoprotective compounds found in botanical sources. International Journal of Pharmacy and Pharmaceutical Sciences, 8(3): 13-23.

Suanarunsawat, T., Ayutthaya, W. D. N., Thirawarapan, S., Poungshompoo, S. (2014). Antioxidative, anti-hyperglycemic and lipid-lowering effects of aqueous extracts of Ocimum sanctum L. leaves in diabetic rats. Food and Nutrition Sciences, 5: 801-811.

Saroya, A.S. (2011). Herbalism, Phytochemistry and Ethnopharmacology. Science Publishers, Enfield. 430 p. 
Simon, J.E., Reiss-Bubenheim, D. Joly, R.J., Charles, D.J. (1992). Water stress-induced alterations in essential oil content and composition of sweet basil. Journal of Essential Oil Research, 4(1):7175 .

Singh, A.P., (2002). A Treatise on Phytochemistry, Emedia Science Ltd, 166 p. 